\title{
Take Five, a nutrition education intervention to increase fruit and vegetable intakes: impact on consumer choice and nutrient intakes
}

\author{
David N. Cox ${ }^{1}$, Annie S. Anderson ${ }^{2}$, Joanna Reynolds ${ }^{1}$, Susan McKellar ${ }^{2}$, Michael E. J. Lean ${ }^{2}$ \\ and David J. Mela ${ }^{1}$ \\ ${ }^{1}$ Consumer Sciences Department, Institute of Food Research, Reading RG6 6BZ, UK \\ ${ }^{2}$ Department of Human Nutrition, University of Glasgow, Glasgow G31 2ER, UK
}

(Received 25 September 1997 - Revised 14 January 1998 - Accepted 6 February 1998)

\begin{abstract}
This study reports results from a randomized controlled intervention trial, focusing on: (1) the identification of successful consumer strategies for increasing fruit and vegetable intakes to the recommended levels of more than five $(80 \mathrm{~g})$ portions per day and (2) impact on overall diet and nutrient intakes. Adult men and women $(n$ 170) fulfilling the main recruitment criterion of eating less than five fruit and vegetable portions per day but contemplating increasing intakes were recruited. Complete valid dietary data was provided by 101 intervention (fifty-nine estimated fruit and vegetable intakes, and forty-two simultaneous weighed total dietary and estimated fruit and vegetable intakes) and twenty-four control subjects (weighed total dietary intakes). Intervention advice included the specific association of high fruit and vegetable intake with reduced risk of disease, practicalities, and portion definition with a target intake of greater than five $80 \mathrm{~g}$ fruit and vegetable portions per day for 8 weeks. There were significant effects $(P<0.001)$ on weighed intakes of fruit and vegetables in the intervention group, rising from 324 (SE 25) to 557 (SE 31) g/d and reflected by validated portion measures at 8 weeks intervention. Successful strategies chosen by 'achievers' of the target intake (65\% of subjects) were conventional (fruit as a snack, vegetables with main meals etc.) and favoured fruit. There were significant increases in percentage energy from carbohydrate (from sugars not starch), vitamin $\mathrm{C}$, carotenes and NSP and there was a significant decrease in percentage energy from fat for subjects who had high fat intakes $(>35 \%$ energy) at baseline. Follow-up self-reported measures at 6 and 12 months indicated mean intakes of 4.5 and 4.6 defined portions/d respectively, suggesting some sustainable effect. In conclusion, the intervention led to significant increases in fruit and vegetable intakes largely via conventional eating habits, with some desirable effects on macro- and micronutrient intakes.
\end{abstract}

Fruit and vegetables: Consumer choice: Nutrient intake: Nutritional intervention

Dietary recommendations around the world are consistent (Cannon, 1991) in advocating high intakes of fruits and vegetables to help prevent a wide range of chronic dietrelated diseases, including cardiovascular diseases and cancers. The World Health Organization (1990) suggests a minimum daily fruit and vegetable intake of $400 \mathrm{~g}$ (excluding potatoes) and this has been translated into approximately five portions per day, assuming a mean of $80 \mathrm{~g} /$ portion (Williams, 1995). However, current intakes in many Western nations are considerably less. For example, in the USA it has been estimated that only $20 \%$ of adults meet this minimum goal (Serdula et al. 1995), and in Scotland it may be as low as 3\% (Anderson et al. 1994a). Despite increasing emphasis on the promotion of fruit and vegetables, purchasing of total fruit and vegetables in the UK has declined slightly from $2193 \mathrm{~g} /$ person per week in 1992 to $2081 \mathrm{~g} /$ person per week in 1996 (Ministry of Agriculture, Fisheries and Food, 1997).

Recent health campaigns have focused on promoting intakes of at least five portions of fruit and vegetables daily. In the UK, campaigns promoting fruit and vegetables in general terms (Health Education Authority, 1992) or specifically linking fruit and vegetables to reducing the risk of cancer (World Cancer Research Fund, undated) have an unknown, but probably small, impact. Whilst both approaches have included some practical advice (e.g. recipes) their potential effectiveness, to our knowledge, has never been evaluated. Little is known about which practical strategies consumers might choose or prefer to adopt to attain recommended intake targets. Tools and approaches used in the large-scale USA '5-a-day' programme cannot necessarily provide direct practical 
guidance for the UK as they are often culturally specific to particular regions, sectors or target groups (Havas et al. 1995). In the UK it is not known whether consumers trying to increase current intakes would have a greater preference for fruit or vegetables, on what occasion they would choose to eat them, e.g. snack or main meal or meal component, and how much these choices would contribute to achieving dietary guidelines. This information might be incorporated into public health messages for use by health promotion agencies, producers, retailers and caterers.

Similarly, there is no information on whether consumers' choices for increasing fruit and vegetable intakes would have a desirable impact on macro- or micronutrient intake. It has been postulated that increasing intakes of fruit and vegetables might lead to desirable changes in reducing the percentage energy from fat, but previous studies have provided mixed results. Anderson et al. (1994a) suggested positive associations between high fruit and vegetable intakes and lower percentage energy from fat, whilst Kant et al. (1992) found no clear relationship. Also, whilst fruit and vegetables are potentially potent sources of antioxidants and NSP, it is not known whether free-living consumers, attempting to increase fruit and vegetable intakes, would choose items that made significant changes to the intakes of these putative protective components.

The aim of the present study was to report the food choices and consequent nutrient intakes of consumers participating in an 8-week educational-intervention aimed at increasing intake of fruit and vegetables to more than five $(80 \mathrm{~g})$ portions $(>400 \mathrm{~g})$ daily.

\section{Methods}

A market research company was engaged to randomly recruit adults (16-65 years) in the city centres of Reading and Glasgow. Respondents were asked a series of questions about their food intake, including portions of fruit and vegetables. Subjects ( $n$ 170) were recruited on the basis that they were resident in either of the two locations, were not vegetarians, consumed less than five defined fruit and vegetable portions per day (and at least one portion per day), but were contemplating increasing their consumption (Prochaska \& DiClemente, 1984) and were willing to take part in 'a food study'. Before intervention, subjects were not informed that the study focused on fruit and vegetables, and control subjects were only informed after the study was completed. Subjects were paid only as compensation for recording data at the end of the study and no financial incentives were provided to purchase more fruit and vegetables. The project was approved by the Institute of Food Research Human Research Ethics Committee and Greater Glasgow Community/Primary Care Local Research Ethical Committee.

In the summer of 1995 , the 170 subjects were randomly allocated to one of three groups: intervention group A provided simultaneous self-reported weighed total dietary inventories and estimated fruit and vegetable portion intakes; intervention group B provided only estimated intakes of selected food items and fruit and vegetable portion intakes. The intervention programme (see pp. 124125) was exactly the same for both groups. The two intervention groups A and B differed only in methods of dietary data collection as resources limited the number of subjects weighing intakes. Group C provided self-reported weighed total dietary inventories and acted as a control for any secular changes in intakes, or study participation effects and as a comparison for intervention effects. A smaller sample size for group $\mathrm{C}$, relative to intervention groups $\mathrm{A}$ and $\mathrm{B}$, was chosen to reflect the fact that minimal changes over time would be expected from controls, while differential responses by intervention subjects would lead to increased variance within these groups during the intervention period.

Face-to-face instruction in weighed dietary methods and estimated portion recording of selected food items (including fruit and vegetables) at baseline were undertaken by the authors (ASA, DNC, JR, SM). Weights and heights were measured pre- and post-intervention (Seca scales and stadiometer (Model 7120; Seca Ltd, Birmingham, UK); or Nivotoise stadiometer (CMS Weighing Equipment Ltd., London, UK) and Salter 951 lithium digital scales (Model no. 951, Salter Housewares Ltd., Kent, UK)) to assess weight changes, and allow for calculation of BMI $\left(\mathrm{kg} / \mathrm{m}^{2}\right)$ and estimated BMR (Department of Health, 1991). A questionnaire assessing perceived barriers to increasing fruit and vegetable intake was administered both immediately pre- and post-intervention to all intervention subjects and is reported elsewhere (Anderson et al. 1998). Socio-demographic data were collected on all subjects.

The intervention target was to exceed five portions per day of total fruits, vegetables and defined vegetable-dishes (excluding potatoes, products with added fruit, and counting a maximum of one portion of fruit juice per day). Intervention subjects (groups A and B) participated in an 8-week intervention programme with three features: (1) educational approaches (on how to achieve five portions per day) in the form of a 'fruit and vegetables for health' lecture, leaflets, question-and-answer sessions, and portion definition; (2) motivational approaches in the form of refrigerator reminder boards, magnets, lunch boxes, recipes, and tasting sessions and (3) behavioural approaches in the form of a self-monitoring diary record (Fig. 1; Cox et al. 1997) of number of portions eaten, occasions and strategy used, (e.g. 'fruit as a snack', 'two portions of vegetables with main meals', vegetable-based main dish etc.). Details of this tool and its validation as a measure of fruit and vegetable intakes have previously been published (Cox et al. 1997). Twelve such strategies for increasing fruit and vegetable intake were listed and in addition subjects were free to chose their own strategies (noting them on the forms in spaces provided). Subjects completed the charts on three occasions during the intervention on week 1 (7d), week 4 (4d) and week 8 (7d). Subjects completed one chart per day and this measuring tool proved to have good validity relative to the simultaneous weighed inventories (Cox et al. 1997). In addition, weighed total dietary intakes from intervention group A and control group C subjects provided assessment at baseline $(7 \mathrm{~d})$, intervention weeks $4(4 \mathrm{~d})$ and $8(7 \mathrm{~d})$. Two of the authors (DNC, ASA) personally instructed subjects in the method and checked completed records with subjects after each round of data collection. 
Intervention group A ( $n$ 42)

\begin{tabular}{|c|c|c|c|c|c|c|c|c|c|c|}
\hline Week... & 0 & $T$ & 2 & 3 & 4 & 5 & 6 & 7 & 8 & \\
\hline \multicolumn{10}{|c|}{$\begin{array}{l}\text { Screening: } \\
\text { 'hidden' portion assessment }\end{array}$} & Body weights \\
\hline & $\begin{array}{l}7 \mathrm{~d} \text { weighed } \\
\text { intakes } \\
\text { Body weight } \\
\text { and heights }\end{array}$ & $\begin{array}{l}7 \mathrm{~d} \text { portions } \\
\text { measure } \\
\text { ts }\end{array}$ & & & $\begin{array}{l}4 \mathrm{~d} \text { weighed } \\
\text { intakes } \\
4 \mathrm{~d} \text { portions } \\
\text { measure }\end{array}$ & & & & $\begin{array}{l}7 \mathrm{~d} \text { weighed } \\
\text { intakes } \\
7 \mathrm{~d} \text { portions } \\
\text { measure }\end{array}$ & \\
\hline
\end{tabular}

Intervention group $\mathrm{B}$ ( $n$ 59)

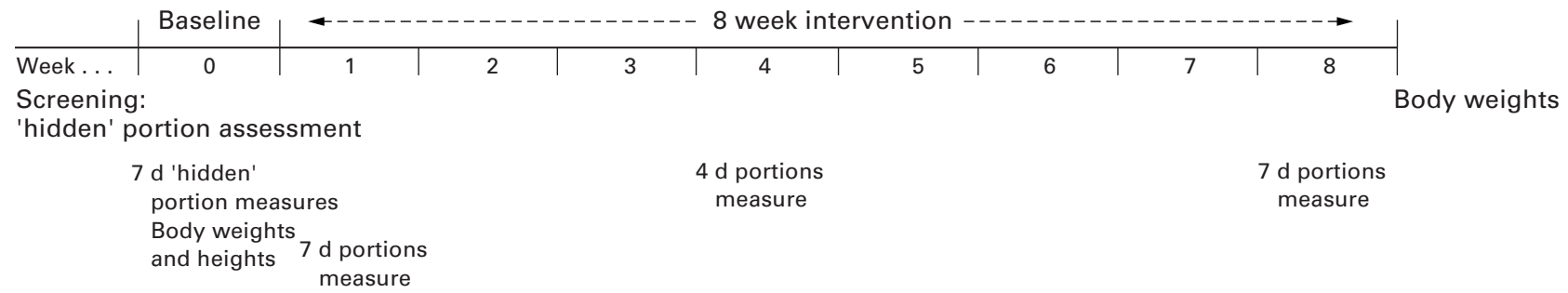

Control group C ( $n$ 24)

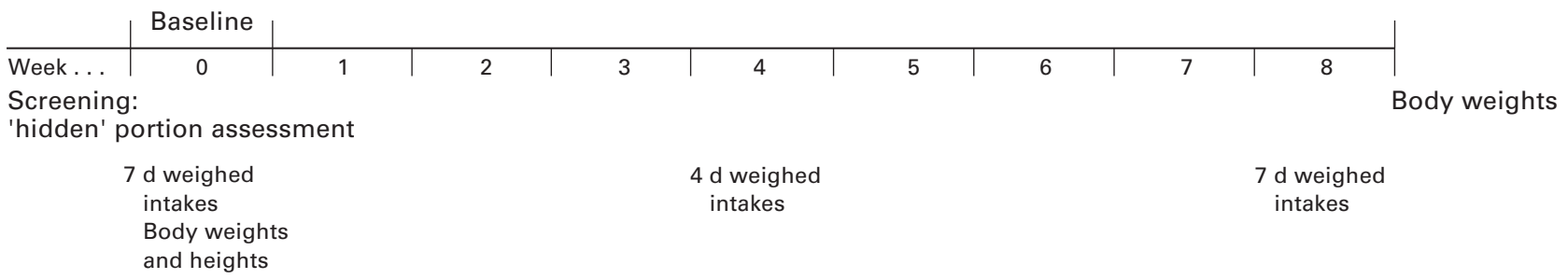

Fig. 1. Design, anthropometric and dietary assessment schedule of an 8-week controlled intervention trial to increase the intake of fruit and vegetables.

The design and dietary assessment schedule are described in Fig. 1 and the two principal dietary measurements and consequent estimated nutrient intake changes are the focus of the present paper.

Subjects' weighed records were coded by trained personnel (with postgraduate nutrition qualifications) and analysed using the Institute of Food Research food composition database (using data from the UK National Nutrient Databank, 1995, Royal Society of Chemistry, Cambridge, UK). When foods were eaten out of the home, self-reported estimations using approximate household measures or photographs of servings (Eddington et al. 1989) were used and later converted to weights. Food codes and weights were double-entered onto spreadsheets (Excel version 4.0, Microsoft Corporation, Redmond, WA, USA) and compared and corrected (with reference to the diaries) for differences. Weights of fruits and vegetables were calculated using food group codes that were adjusted to exclude any vegetable-dish that consisted of potato or (mostly) cereals (for example, potato croquettes or pizza) or 'fruit desserts' (for example, fruit pies or yoghurts). Only one portion of fruit juice per day counted as part of the fruit and vegetable intake target and a portion of $200 \mathrm{ml}$ juice was converted to a nominal $80 \mathrm{~g}$ portion. Subjects with weighed baseline reported energy intakes less than estimated BMR $\times 1 \cdot 1$ were excluded as significant under-reporters (Goldberg et al. 1991).

In addition, intervention subjects were followed-up at 6 months (the subsequent winter) $(n$ 100) and at 12 months (the following summer) ( $n$ 64) using a postal questionnaire (with portion definitions). The primary aim was to see whether the intervention had any sustainable effect and, therefore, asked subjects to state how many defined portions were being consumed.

Descriptive statistics, $t$ tests and repeated-measures ANOVA were computed using SPSS version 6.1, 1994 (SPSS Inc., Chicago, IL, USA). Significance levels reported for effects are exact with a minimum criterion for statistical significance of $P<0.05$.

\section{Results}

From 138 intervention subjects, 101 (73\%) provided complete valid fruit and vegetable portion data. Of these, fortytwo subjects, were in group A which additionally provided complete valid weighed dietary data. Of an original sixtyfive group A recruits, ten failed to meet under-reporting criteria and thirteen failed to provide complete data. The other fifty-nine intervention subjects (group B) provided complete portion measures data. Of an original seventy-four group B recruits in this group, fifteen failed to provide complete data. From thirty-two controls (group C) twentyfour $(75 \%)$ provided complete valid weighed total dietary data. Of an original thirty-two group $\mathrm{C}$ recruits, four failed to meet under-reporting criteria and four failed to provide complete data. Study drop-outs were de-briefed, with most reporting 'lack of time to take part in the study' (work, 
Table 1. Characteristics of subjects completing an 8-week trial ${ }^{\star}$

\begin{tabular}{|c|c|c|}
\hline Variable & $\begin{array}{l}\text { Intervention } \\
(n \text { 101) }\end{array}$ & $\begin{array}{l}\text { Controls } \\
(n \text { 24) }\end{array}$ \\
\hline Age (years) & $35 \cdot 4$ (SE $1 \cdot 2)$ & $30 \cdot 5$ (SE $2 \cdot 8)$ \\
\hline $\begin{array}{l}\text { Sex: } \\
\quad \text { female (\%) }\end{array}$ & 74 & 58 \\
\hline Non-manual occupation (\%) $\dagger^{\star}$ & 74 & 67 \\
\hline $\begin{array}{l}\text { Gross household income/year: } \\
\quad<£ 10,000(\%) \\
£ 10,000-£ 20,000(\%) \\
£ 20,000-£ 30,000(\%) \\
>£ 30,000(\%)\end{array}$ & $\begin{array}{l}31 \\
25 \\
26 \\
19\end{array}$ & $\begin{array}{l}26 \\
35 \\
26 \\
13\end{array}$ \\
\hline Economically inactive (\%)‡ & 24 & 25 \\
\hline BMI $\left(\mathrm{kg} / \mathrm{m}^{2}\right)$ & $25 \cdot 1$ (SE 3.4) & $22 \cdot 3(\operatorname{SE} 0 \cdot 7)$ \\
\hline
\end{tabular}

* No statistical difference between intervention and control group.

†Occupation of head of household (Office of Population Censuses and Surveys, 1991).

‡ Includes unemployed, retired and students.

domestic pressures, vacation) and only two subjects reporting 'cost of increased fruit and vegetable intake' as a reason for preventing completion. Subject profiles of those providing complete valid data are reported in Table 1 and whilst no significant differences were found between the intervention and control groups the latter were slightly younger and leaner. The sample was predominantly female and from non-manual households; however, subjects' reported income was evenly spread.

\section{Effect of the intervention on reported portions of fruit and vegetables consumed}

The 'portions measure' tool was reasonably well correlated with weighed intakes $(r 0.73)$, although using the conventional conversion of $80 \mathrm{~g} /$ portion (Williams, 1995), the tool tended to underestimate intakes relative to weighed measures (Cox et al. 1997). By the portions measure ( $n$ 101) the mean intake of intervention subjects was 5.4 (SE 0.2) portions per day at 8 weeks intervention, and $74 \%, 71 \%$, and $65 \%$ of intervention subjects achieved the target of greater than five portions per day in weeks 1,4 and 8 respectively. There were few differences in the rankordering of the chosen strategies between those that achieved or failed to achieve greater than five portions per day, or between sites of Glasgow and Reading, or between males and females. However, a greater proportion of Reading subjects $(75 \%)$ were successful in raising intakes to above five portions per day compared with Glasgow subjects $(49 \%)$ at 8 weeks intervention. Strategies for increased intakes favoured by achievers (mean number of portions $6.44($ SE $0 \cdot 21)$ ), ranked in order of contribution to intakes, are presented in Table 2. Seven other strategies were used but it was clear that the target of greater than five portions per day was achieved within conventional eating habits. Despite promotion of 'vegetable dishes' the mean contribution of this approach was only $0 \cdot 22$ portions per day, ranking equal sixth with 'fruit on breakfast cereal'.

Weighed dietary intake results are reported below for all intervention group A $(n$ 42) and control group C subjects (n 24) providing valid data as described in the methods.
Table 2. Strategies used to increase fruit and vegetable intake by subjects achieving greater than five portions per day at 8 weeks intervention*

(Mean values with their standard errors for sixty-four subjects)

\begin{tabular}{lccc}
\hline & \multicolumn{2}{c}{ No. portions } & \\
\cline { 2 - 3 } Strategy used & Mean & SE & \% of total intake \\
\hline Fruit as a snack & 1.56 & 0.11 & 24 \\
Vegetables with a main meal & 1.38 & 0.10 & 21 \\
Fruit as a dessert & 0.90 & 0.09 & 14 \\
Fruit juice† & 0.72 & 0.04 & 11 \\
Salad & 0.51 & 0.05 & 8 \\
Top five strategies & 5.07 & & 78 \\
\hline
\end{tabular}

${ }^{*}$ For details of intervention techniques, see pp. 124-125.

† Maximum of one glass daily 'counted' as a portion.

These results were not changed when analyses were restricted to those intervention group A subjects achieving the target fruit and vegetable intake $(81 \%, n 34)$.

The intervention effect on mean daily intake of fruit and vegetables was dramatic (Fig. 2) with a significant $(P$ $<0.001 v$. control) increase from baseline, from a mean of 324 (SE 25) g to 557 (SE 31) g at 8 weeks intervention. Most of this increase came from greater fruit consumption, from a baseline mean of 148 (SE 16) $\mathrm{g}$ to a mean of 354 (SE 20) $\mathrm{g}$ at week 8 . For the same period mean vegetable intake rose from only 137 (SE 11) g to 160 (SE 12) g and intakes from vegetable dishes rose only from 28 (SE 6) to 47 (SE 7) g.

For Glasgow group A intervention subjects ( $n$ 19) fruit and vegetable intakes rose, from a baseline mean of 291 (SE 32) g/d, to 554 (SE 41) g/d at 8 weeks intervention, compared with the Reading group A subjects' ( $n$ 23) baseline mean of 351 (SE 38) $\mathrm{g} / \mathrm{d}$ which increased to 568 (SE 36) $\mathrm{g} / \mathrm{d}$ at 8 weeks intervention. The greater magnitude of difference reported by the Glasgow subjects was not however, statistically significantly different $(P=0.599$, two-tailed $t$ test).

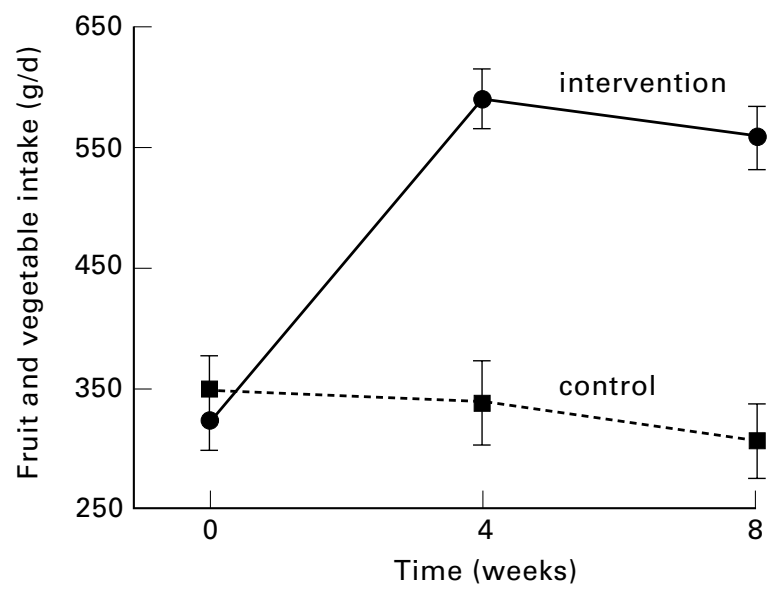

Fig. 2. Effect of intervention on fruit and vegetable intake. Values are mean weighed daily intakes, with their standard errors represented by vertical bars, for the control group $(n 24 ; \cdots \mathbf{n} \cdots)$ and the intervention group (group A, $n 42 ;-\bullet$ ) at baseline ( 0 weeks) and after 4 weeks and 8 weeks of intervention. 


\section{Energy and macronutrient intakes}

Energy and macronutrient intakes during the trial are shown in Table 3. Total reported energy intakes declined significantly $(P=0.003)$ over time for both intervention and control subjects but differences were not significant between the groups suggesting an overall measurement effect possibly related to similar levels of minor underreporting or secular changes in intakes.

Overall the percentage energy from fat declined in the intervention group more than in controls, but this was not statistically significant. However, amongst those that were reporting greater than $35 \%$ energy from fat at baseline (intervention $n 22$, control $n$ 17), a statistically significant intervention effect was found. These intervention subjects' reported mean percentage energy from fat declined from a baseline of $39 \cdot 1$ (SE 0.69$) \%$ to $35 \cdot 1$ (SE 1.4) \% at week 4 and to 34 (SE 1.43$) \%$ at week $8(P=0.039 v$. controls: $38 \cdot 6$ (SE $0.51) \% ; 38.8($ SE 0.52$) \%$ and 37.6 (SE 0.66$) \%$ respectively at these time points).

A significant $(P=0 \cdot 011)$ increase in percentage energy from carbohydrate was found with significant $(P$ $<0.001$ ) increases coming from fructose and sugars (other than sucrose and lactose). There was a slight and nonsignificant reduction in percentage energy from starch in the intervention group. There were no statistically significant effects on sucrose or lactose intake.

\section{Antioxidant vitamins and NSP}

Limited composition data (UK Nutrient Databank, Royal Society of Chemistry, Cambridge, UK) allow for analysis of some vitamins with antioxidant properties (Table 4). Intervention effects on vitamin $\mathrm{C}$ were considerable, even from a high baseline intake. Effects on carotenes $(\beta$ and $\alpha$ combined) were less dramatic but also statistically significant $(P=0 \cdot 029)$, with virtually no change amongst controls. Vitamin $\mathrm{E}$ intake was stable in both the intervention and control groups. The intervention had a significant effect $(P$ $<0.001$ ) on intake of NSP (measured by the Englyst method) (Table 4) although the mean intakes were still below the current recommendation of $18 \mathrm{~g} / \mathrm{d}$ (Department of Health, 1991).

\section{Body weight}

At week 8, the change from baseline in mean body weight for group A intervention subjects ( $n$ 42) was $+1 \cdot 3 \mathrm{~kg}$, not significantly different $(P=0 \cdot 78$, two-tailed $t$ test $)$ from the control subjects' ( $n$ 24) mean weight change of $+1 \cdot 5 \mathrm{~kg}$. Both of these groups made small but significant (intervention group $P=0.032$; control group $P=0.041$, both two-tailed $t$ test) increases in weight from baseline. These changes in body weights were unlikely to be attributable to the intervention as reported energy intakes fell (in all subject groups).

Table 3. Daily energy intakes and percentage energy from macronutrients at baseline and after 4 and 8 weeks intervention to increase fruit and vegetable intake*

(Mean values with their standard errors for forty-two (intervention) and twenty-four (control) subjects)

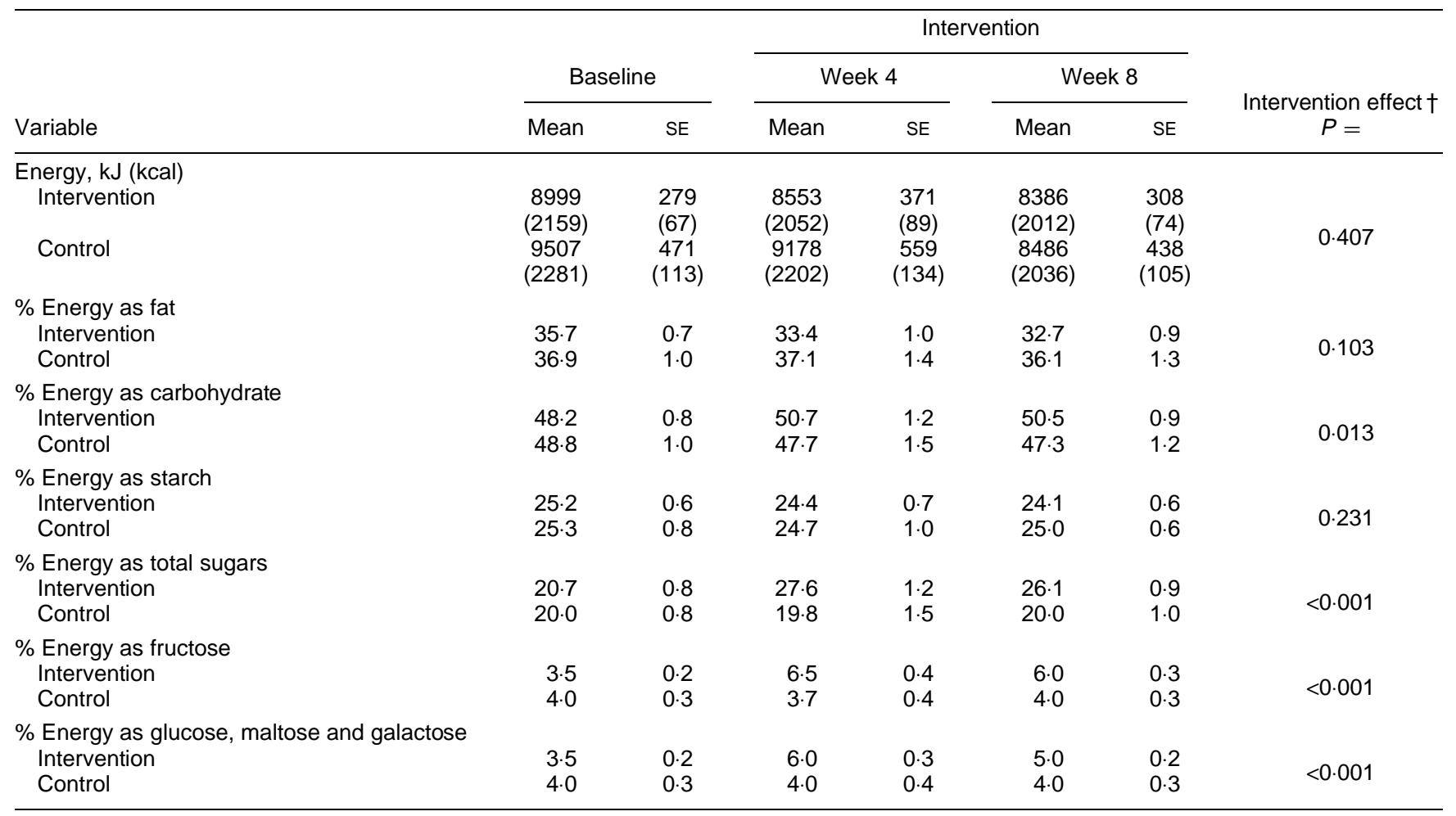

${ }^{*}$ For details of subjects, intervention techniques and dietary intake analysis procedures, see. pp. 124-126.

†ANOVA, group $\times$ time effect. 
Table 4. Daily intakes of selected antioxidant vitamins and NSP (measured by the Englyst method) at baseline and after 4 and 8 weeks intervention to increase fruit and vegetable intake*

(Mean values with their standard errors for forty-two (intervention) and twenty-four (control) subjects)

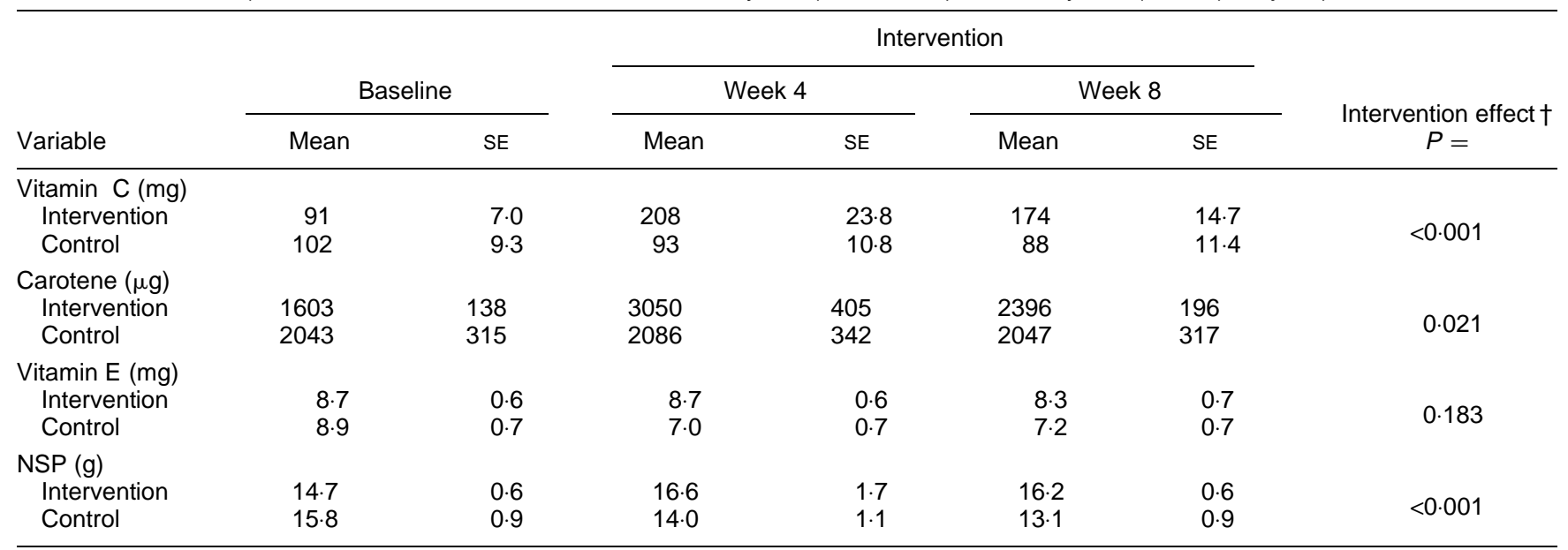

${ }^{*}$ For details of subjects, intervention techniques and dietary intake analysis procedures, see pp. 124-127.

† ANOVA, group $\times$ time effect.

\section{Follow-up}

To assess changes in reported fruit and vegetable portion intakes from pre-intervention to 1 year after intervention, Table 5 reports daily portions at pre-intervention, at the end of the intervention, and estimates at 6 and 12 months after intervention. There were small but significant $(P<$ $0 \cdot 001)$ declines in intake 6 months after the intervention study, but these self-reported intakes were significantly $(P$ $<0.001)$ greater than baseline estimated intakes. Furthermore, there were no reports of further significant declines 1 year after intervention. At the end of the trial, $65 \%$ of subjects reported eating five or more portions per day, compared with $45 \% 6$ months after and $44 \% 12$ months after intervention.

\section{Discussion}

The educational, motivational and behavioural intervention used here succeeded in raising intakes of fruit and vegetables to above the minimum recommended target of five portions per day for the majority of intervention subjects in Reading and almost half those in Glasgow by the portions measure. This measure tended to underestimate intakes relative to weighed intakes. It should also be noted that these measures restricted counting of fruit juice consumption to one portion per day because of the desire to encourage variety (Williams, 1995), and because juice is only an extract of fruit and therefore lacks components of the whole fruit, e.g. NSP. In practice these subjects consumed more than a mean of one portion per day, so that actual intakes were higher than reported here, which may have led to even more significant effects on vitamin $\mathrm{C}$ and carotene intakes. In their definitions for calculating fruit and vegetable intakes, other interventions and public health messages, for example the US '5-a-day' program (D Buller, personal communication), have not been so restrictive towards fruit juice but have, at the same time, restricted certain vegetables.

Whether fruit, a generic item with limited advertising budgets and availability, can replace heavily marketed and branded products as a snack is unknown and remains a

Table 5. Self-rated intake assessments of portions of fruit and vegetables reported at the end of the 8-week study, and after 6 months (subsequent winter) and 12 months (following summer) follow-upt

(Mean values with their standard errors for intervention subjects for whom data was available at all time points $(n 59))$

\begin{tabular}{|c|c|c|c|c|c|c|c|}
\hline \multicolumn{2}{|c|}{$\begin{array}{l}\text { Pre-intervention } \\
\text { no. portions } \neq\end{array}$} & \multicolumn{2}{|c|}{$\begin{array}{l}\text { End of study } \\
\text { no. portions§ }\end{array}$} & \multicolumn{2}{|c|}{$\begin{array}{l}\text { After } 6 \text { months } \\
\text { no. portions\| }\end{array}$} & \multicolumn{2}{|c|}{$\begin{array}{l}\text { After } 12 \text { months } \\
\text { no. portions }\end{array}$} \\
\hline Mean & SE & Mean & SE & Mean & SE & Mean & SE \\
\hline $3 \cdot 3^{* * *}$ & 0.3 & $5 \cdot 2^{\star \star \star \star}$ & 0.2 & 4.5 & 0.2 & 4.6 & 0.2 \\
\hline
\end{tabular}

Mean values were significantly different from those at 6 and 12 months after intervention, ${ }^{* \star *} P<0.001$.

†For details of subjects and intervention techniques see pp. 124-125.

$\ddagger$ Estimate made at recruitment screening.

$\S$ Mean of $7 \mathrm{~d}$ validated records.

II Self-estimates of average intakes at 6 and 12 months after study. 
challenge for producers and retailers. Furthermore there are limited data on consumer's expectations of snacks. Evidence from the some of the authors' earlier work (Anderson et al. 1994b) suggests that fruit is not perceived as 'filling', which may be a requirement for snacks for some consumers. The intervention advice reported here attempted to promote fruit as a 'low calorie' snack and this may only appeal to the weight conscious and 'restrained eaters' (Butler et al. 1996). Further work is required to discover whether 'low calorie' would be a successful promotional message only for certain types of consumers or would have a broader appeal. Hedonistic qualities of foods used as snacks such as 'rewarding', 'pleasurable' or other sensory attributes of higher-fat snack items also need to be explored relative to the promotion of fruit as a regular snack.

Some reports (Bibby, 1983; Burt \& Ismail, 1986) have expressed concerns about consumption of fruits and possible effects on an increased incidence of dental caries. Despite well documented evidence on the association of high fruit juice consumption with greater development of caries in infants and children (reviewed by Dennison, 1996), there is a need to explore concerns over fruit consumption and dental caries in adults within a public health context.

It is important to note that three of the 'easiest' strategies (Anderson et al. 1998) were in fact the most popular for achieving '5-a-day'. This suggests that whilst these may be effective, practical routes for some, they may be problematic for others (i.e. non-achievers) and guidance and facilitation may be helpful. For example, 'achievers' found incorporation of vegetables into main meals easier than non-achievers and this may have implications for the possible changes in social settings of meals. There is a dearth of published information on whether the UK 'traditional meal' of 'meat and vegetables' is regularly and broadly consumed. Clearly knowledge of such eating patterns would be helpful in promoting 'two defined portions with main meals' which may lead to more desirable nutrient intakes.

The promotion of Asian, Mediterranean and UK vegetable-dishes (tasting and recipes) did not lead to these contributing substantially to fruit and vegetable intakes, despite high ratings for the recipes (AS Anderson, unpublished results). A nationwide survey (Cox et al. 1998) revealed that consumption of vegetable dishes was low, with attitudes as the strongest predictor of increased consumption. Qualitative data from this study revealed taste as a major factor in rejection of pulse and bean dishes (excluding baked beans), with possible consequences for NSP intakes. This is in contrast to qualitative work (Kilcast et al. 1996), on small groups of consumers, which suggested that 'conventional' eating habits would be a barrier to increased vegetable consumption and reported a high popularity of vegetable dishes. Given that most of the increase in intakes in the present study came from fruit, and the conflicting reports on the popularity of vegetable dishes, perhaps more commercial promotion of vegetable dishes is required before such foods can become a vehicle for increased vegetable intakes within public health messages.

The particularly dramatic increase in fruit relative to vegetable intakes during the intervention period may be related to seasonality, as follow-up data revealed that there was a clear perception that less fruit was eaten in winter. Only further research could determine whether increases would come more from vegetables if consumers were asked to increase their intakes of fruit and vegetables during other seasons, and assess the consequences for nutrient intakes.

Our data reveal a slight non-significant reduction in percentage energy from fat for the whole intervention sample, which is encouraging, but more notable were significant reductions from those who had reported intakes of greater than $35 \%$ energy from fat at baseline, intakes typical of UK consumers. This seems to suggest that fruit and vegetables could play some role in reducing fat consumption in those that have high-fat diets. Given the substantial increase in fruit consumption it is not surprising that there was a rise in energy from fructose and other sugars (excluding sucrose and lactose). Our results suggesting reduced energy intakes from fat are encouraging and indicate that public health messages concerning fat reduction should incorporate encouragement of greater fruit and vegetable consumption. However further trials should be conducted to confirm whether such macro-nutrient changes might occur with increased fruit and vegetable intakes. It is possible, for example, that if greater vegetable consumption (relative to fruit) was chosen in another season e.g. winter, positive effects would not be found because of added fats (e.g. butter, margarine) or the use of cooking oils.

Changes in antioxidant vitamins, for which there are limited food composition data, should be interpreted as only indicative of possible effects of increased intakes, as variations in sources, cooking methods, preparation, availability and absorption affect composition and bioavailability as eaten (Holland et al. 1991, 1992; Bergström, 1996). However dramatic increases in vitamin C, from a high baseline level, could be attributed to the rise in fruit intakes which are not likely to be affected by cooking losses. The rise in carotene, though significant, was not as dramatic as vitamin $\mathrm{C}$ and may reflect the relatively low carotene content of fruits and many vegetables actually chosen by UK consumers (DN Cox, unpublished results). It is unfortunate that the UK nutrient databank lacks, as yet, more comprehensive composition data on carotenoids and other phyto-chemicals; however, $\beta$ - and $\alpha$-carotenes may act as a proxy measure for intakes of other protective components (Gillman, 1996). It is important to note that recent data (Zino et al. 1997) demonstrated that very high intakes of fruit and vegetables were associated with significant changes in plasma concentrations of $\beta$ - and $\alpha$-carotene and vitamin $\mathrm{C}$, with potential implications for reduced risk of some cancers. Other recent data (Key et al. 1996), on a large UK cohort sample of vegetarians and health-conscious adults, indicated that consumption of unspecified fresh fruit was clearly associated with reduced mortality from ischaemic heart disease, cerebrovascular disease and all causes combined. The protective effects of fruit and vegetables may be confounded by the associated status and behaviour of people likely to be consuming diets rich in fruit and vegetables (Nestle, 1996); however, this is beyond the scope of the present paper.

NSP intakes rose significantly after the intervention and, although this is encouraging, mean levels still fell below the average recommendation of $18 \mathrm{~g} / \mathrm{d}$ (Department of 
Health, 1991). It seems unreasonable to expect such recommendations to be met from increased fruit and vegetable intakes alone, but rather from a combination of increased fruit and vegetables with, for example, whole-grain cereal products. Given the slight and non-significant reduction in starch intakes, fruit and vegetable intakes still generated substantial increases in NSP intakes. It is possible that greater NSP intakes could be achieved from increased vegetable intakes rather than the increased fruit intakes chosen by these subjects.

The similar, slight but significant increases in mean body weight in all groups when reported energy intakes fell over time are difficult to account for. It is possible that summer vacations and hot weather during the intervention period may have had some effect on reduced energy expenditure leading to positive weight gain. However, it is more likely that there was some reduced reporting or artificially low intakes during later diet recording periods (Mela \& Aaron, 1997).

The subjects were mostly female and from non-manual households and individuals with these characteristics are most likely to be contemplating dietary change and possibly succeeding in making such a change (Curry et al. 1992; Glanz et al. 1994). We acknowledge that, whilst differences in the characteristics of the intervention and control groups were not statistically significant, there were some apparent differences with regard to the proportions of females, mean ages and BMI which may have had some influence on predisposing the intervention group to increasing intake of fruit and vegetables. However, whilst sex has been found to be a significant factor within the 'stages of change' model with regard to fat reduction (Steptoe et al. 1996), i.e. females are more likely to be contemplators of dietary change, this was not found for age or BMI status. Whilst one main objective was to ascertain which strategies would be chosen in order to raise intakes, care should be taken in assuming that such strategies might be chosen by different sections of the population and a validation study has been undertaken by the authors to examine this.

The greater proportion of subjects in Reading 'achieving' intakes greater than five portions per day, may be attributed to the relatively greater increase required by the subjects in Glasgow from lower baseline intakes (as recorded by the weighed intakes). It is encouraging to note that the change in intakes was similar at both sites and that almost half the subjects in Glasgow increased their intakes to above the recommended amount.

Table 5 shows that, despite a significant fall in reported portions consumed 6 months after intervention, the amount remained close to the recommended minimum of five portions per day and significantly greater than the mean estimated daily portion intake at pre-intervention recruitment screening. At 6 months after intervention, $45 \%$ of these subjects (one unknown) reported eating five or more portions per day, and 12 months after, $29 \%$ (sixty-two unknown) reported eating five or more portions per day. It is therefore concluded that, as far as can be determined, the intervention is likely to have had some sustainable effect on the reported intakes of a considerable proportion of the study sample.

Given the success of this intensive study, further work has been undertaken to validate these findings in a context closer to a public health setting, using worksites as a medium for contacting consumers. We conclude that it was possible to raise intakes to recommended levels of more than $400 \mathrm{~g} / \mathrm{d}$ (five portions per day) through a multimethod intervention targeted at consumers contemplating increasing intakes. Successful strategies were identified as being within conventional eating habits with a distinct preference for fruit. Some desirable effects on dietary macronutrient profile and some antioxidant nutrient and NSP intakes were also apparent.

\section{Acknowledgements}

The authors wish to thank Mr David Bradford, Dr Elizabeth Bowey, Dr Victoria Burley, Ms Louise Lawson, Mr Peter Moore and Ms Miriam de Souza (State Registered Dietitian), Ms Sheila Turner (State Registered Dietitian) for coding weighed diet records; and Ms Lynne Perry for operation of the Institute of Food Research Nutrient Database and Mrs Rachel Stewart for data handling. This project was funded by the Ministry of Agriculture, Fisheries and Food.

\section{References}

Anderson AS, Cox DN, McKellar S, Reynolds J, Mela DJ \& Lean MEJ (1998) Take Five, a nutrition education intervention to increase fruit and vegetable intakes: impact on attitudes towards dietary change. British Journal of Nutrition 80, 133140 .

Anderson AS, Hunt K, Ford G \& Finnigan F (1994a) One apple a day? - fruit and vegetable intakes in the West of Scotland. Health Education Research 9, 297-305.

Anderson AS, Lean MEJ, Foster A \& Marshall D (1994b) Ripe for change: fruit and vegetables in Scotland - current patterns and potential for change. Health Bulletin 52, 51-64.

Bergstrom ILM (1996) Are we measuring what we intend to measure? Different techniques of food preparation and cooking: implications for dietary surveys. Proceedings of the Nutrition Society 55, 671-678.

Bibby BG (1983) Fruits and vegetables and dental caries. Clinical and Preventative Dentistry 5, 3-11.

Burt BA \& Ismail AI (1986) Diet, nutrition and food cariogenicity. Journal of Dental Research 65, 1475-1484.

Butler BA, Wing RR \& Shiffman S (1996) Effect of the number of high-fat and low-fat cues on food choice. International Journal of Behavioural Medicine 3, 42-54.

Cannon G (1991) Food and Health: The Experts Agree. London: Consumers Association.

Cox DN, Anderson AS, Lean MEJ \& Mela DJ (1998) UK consumer attitudes, beliefs and barriers to increasing fruit and vegetable consumption. Public Health Nutrition 1, 61-68.

Cox DN, Anderson AS, McKellar S, Reynolds J, Mela DJ \& Lean MEJ (1997) Measuring fruit and vegetable intakes: is Five-a-Day enough? European Journal of Clinical Nutrition 51, 177-180.

Curry SJ, Kristal AR \& Bowen DJ (1992) An application of the stages model of dietary fat reduction. Health Education Research 7, 120-126.

Dennison BA (1996) Fruit juice consumption by infants and children - a review. Journal of the American College of Nutrition 15, Suppl., S4-S11.

Department of Health (1991) Dietary Reference Values for Food Energy and Nutrients for the United Kingdom. London: HM Stationery Office. 
Eddington J, Thorogood M, Geekie M, Ball M \& Mann J (1989) Assessment of nutritional intake using dietary record with estimated weight. Journal of Human Nutrition and Dietetics 61, 407-414.

Gillman MW (1996) Enjoy your fruits and vegetables. British Medical Journal 313, 765-766.

Glanz K, Patterson RE, Kristal AR, DiClemente CC, Heimendinger J, Linnan L \& McLerran DF (1994) Stages of change in adopting healthy diets: fat, fiber and correlates of nutrient intake. Health Education Quarterly 21, 499-519.

Goldberg GR, Black AE, Jebb SA, Cole TJ, Murgatroyd PR, Coward WA \& Prentice AM (1991) Critical evaluation of energy intake data using fundamental principles of energy physiology: 1. Derivation of cut-off limits to identify under-recording. European Journal of Clinical Nutrition 45, $569-581$.

Havas S, Heimendinger J, Damron D, Nicklas TA, Cowan A, Beresford SAA, Sorenson G, Buller D, Bishop D, Baranowski T \& Reynolds K (1995) 5 a day for better health - nine community research projects to increase fruit and vegetable consumption. Public Health Reports 110, 68-79.

Health Education Authority (1992) Enjoy Fruit and Vegetables. London: Health Education Authority.

Holland B, Unwin ID \& Buss DH (1991) Vegetables, Herbs and Spices. Cambridge: Royal Society of Chemistry/Ministry of Agriculture, Fisheries and Food.

Holland B, Unwin ID \& Buss DH (1992) Fruit and Nuts. Cambridge: Royal Society of Chemistry/Ministry of Agriculture, Fisheries and Food.

Kant AK, Block G, Schatzkin A \& Nestle M (1992) Association of fruit and vegetable intake with dietary fat intake. Nutrition Research 12, 1441-1454.

Key TJA, Thorogood M, Appleby PN \& Burr MI (1996) Dietary habits and mortality in 11000 vegetarians and health conscious people: results of a 17 year follow up. British Medical Journal 313, 775-779.

Kilcast D, Cathro J \& Morris L (1996) Practical approaches to increasing vegetable consumption. Nutrition and Food Science $5,48-51$.
Mela DJ \& Aaron JI (1997) 'Honest but invalid': What the subjects say about recording their food intake. Journal of the American Dietetic Association 97, 791-793.

Ministry of Agriculture Fisheries and Food (1997) National Food Survey 1996. London: HM Stationery Office.

Nestle M (1996) Fruits and vegetables: protective or just fellow travellers? Nutrition Reviews 54, 255-257.

Office of Population Censuses and Surveys (1991) Appendix A. Allocation of standard classification occupational unit groups to social classes and socio-economic groups. In Standard Occupational Classification 1991. London: HM Stationery Office.

Patterson RE, Kristal AR \& White E (1996) Do beliefs, knowledge, and perceived norms about diet and cancer predict dietary change? American Journal of Public Health 86, 1394-1400.

Prochaska JO \& DiClemente CC (1984) The Transtheoretical Approach: Crossing Traditional Boundaries of Change. Homewood, IL: Dow Jones/Irwin.

Serdula MK, Coates RJ, Byers T, Simoes E, Mokdad AH \& Subar AF (1995) Fruit and vegetable intake among adults in 16 states: results from a brief telephone survey. American Journal of Public Health 85, 236-239.

Steptoe A, Wijetunge S, Doherty S \& Wardle J (1996) Stages of change for dietary fat reduction: associations with food intake, decisional balance and motives for food choice. Health Education Journal 55, 108-122.

Williams C (1995) Healthy eating: clarifying advice on fruit and vegetable consumption. British Medical Journal 310, 1453-1455.

World Cancer Research Fund (undated) Dietary Guidelines to Lower Your Cancer Risk. London: World Cancer Research Fund.

World Health Organization (1990) Diet, Nutrition and the Prevention of Chronic Disease. Technical Report Series no. 797. Geneva: WHO.

Zino S, Skeaff M, Williams S \& Mann J (1997) Randomised controlled trial of effect of fruit and vegetable consumption on plasma concentrations of lipids and anti-oxidants. British Medical Journal 314, 1787-1791. 